\title{
O "know-how" artístico
}

\author{
Ana Maria de M. Belluzzo
}

A situação paradoxal das artes visuais, nos dias de hoje, não passa desapercebida aos que delas se ocupam, oferecendo motivos de sobra para que sejam reconsiderados alguns aspectos centrais da sua existência nas sociedades industriais modernas.

Como não notar a figura do artista que persistiu operando em moldes artesanais nos últimos dois séculos, quando o conjunto da produção se transformou definitivamente pela ordem industrial, que o atingiu através dos formatos da indústria cultural e do mercado? $\mathrm{O}$ isolamento do artista, que propiciou o aprofundamento de seu trabalho, foi também uma reclusão na esfera especializada. A obra excêntrica correspondeu, ainda, ao deslocamento da arte das modalidades da produção e difusão dominantes. Por outro lado, quando se indaga sobre os resultados estéticos das novas formas de fazer, constata-se que a completa redefinição simbólica e técnica, realizada com as possibilidades abertas pela moderna tecnologia, não prescinde do momento artesanal. As obras são concebidas enquanto trabalho concreto, por meio de processos internalizados. A cultura industrial, mediatizada por tantos e tão complexos sistemas, não impediu a objetivação artística, embora tenha especializado e compartimentado seus processos. Basta lembrar que o momento de elaboração cinematográfica pode permanecer artesanal, enquanto a produção do filme se viabiliza pela reprodução industrial. Mais do que a base técnica, a organização do trabalho artístico estabelece os limites entre uma etapa e outra. A contribuição dos fotógrafos revelou, por sua vez, ser possível domesticar o instrumento e a máquina, e colocá-los a serviço de uma relação viva e direta com o mundo. Ademais, sobrevive também uma sorte de reprodução artesanal, a reprodução artística como indica a repetição interpretativa dos músicos e atores, cuja experiência pode ser posteriormente registrada e veiculada pelo disco, pelo rádio, pela televisão.

Ao examinar a experiência artística em suas complexas inter-relações com as mudanças na produção, vem à tona, primeiramente, a problemática relação entre arte e trabalho. Ressaltam-se os laços profundos entre arte e artesanato, já manifestos no étimo, sem que se conclua por uma identificação entre ambos, mas sim lembrando a forte correlação histórica, que merece mais atenção à medida que mais nos afastamos no tempo. Surge também a necessidade de precisar alguns marcos gerais da questão e contribuir para uma periodização conveniente a assunto tão amplo.

A imagem que me ocorre ao iniciar esse ensaio é a do historiador que persegue enquadramentos. Procura focalizar a arte no mundo da cultura, da produção, e corre o risco de não apreendê-la ao utilizar categorias extra-artísticas, quando busca entender nexos da arte estruturantes da história. O tempo altera os parâmetros e os enquadramentos fixos acabam por revelar, sob a mesma moldura, fenômenos totalmente transformados. O objeto artístico, tornado objeto técnico, ilustra a história das artes compreendidas entre o artesanato e a indústria. A idéia de um turning point do sistema artesanal a outro industrial, juntamente com a indagação sobre os limites das transformações da arte impõem-se como exigências do assunto.
ANA MARIA DE M. BELLUZZO é professora de História da Arte da FAU-USP. 
Abaixo, a primeira fotografia de que se tem notícia; (Niépce,

1826); à direita, natureza morta com moldes, de Daguerre
As reflexões aqui apresentadas foram feitas em caráter introdutório a um estudo histórico sobre o Liceu de Artes e Off́cios de São Paulo, instituição que foi centro irradiador das artes aplicadas no começo do século. $O$ caso em exame configurava uma experiência tardia da primeira industrialização de base técnica artesanal, dita industrialização manufatureira ${ }^{(1)}$. Acredito que tal estudo tenha colaborado para que concluíssemos pela eliminação dos contornos rígidos que isolam as duas noções, artesanato e indústria, tendo evidenciado as vantagens de se falar em um momento industrial do trabalho artesanal e em um momento artesanal da produção industrial. Procuramos evitar os perigos que oferecem as concepções sistêmicas adotadas a priori. Visualizar o ponto de inflexão, a passagem de um momento a outro, é desenhar noções preliminares e a seguir ultrapassá-las em nome de um conhecimento não-dogmático.

Nessa abordagem, o aspecto técnico das obras adquire uma dimensão privilegiada, por ser capaz de propiciar a aproximação entre a forma dada pelo artista e o estágio de desenvolvimento da produção social.

Mas a meta final é sempre a possibilidade estética da obra, inseparável da objetivação artística, pela qual o homem constrói uma relação de sentido entre ele e o mundo. Afinal, mesmo admitindo a relação problemática entre arte e trabalho, sabemos que o valor artístico de uma obra é inseparável do trabalho humano que ela concretiza. Esta compreensão é cuidadosamente desenvolvida por Giulio Carlo Argan, que insiste que "o conceito de arte não define uma categoria de coisas, mas um tipo de valor. Este, sempre correlacionado com o trabalho humano e suas técnicas, indica o resultado de uma relação entre atividade mental e operativa". Precisa ainda o autor que "o valor artístico de um objeto dá-se na sua forma".

Admitindo que arte e trabalho são noções intrinsecamente históricas e historicamente correlatas, verificamos que é a partir de uma perspectiva contemporânea que a atividade artística propriamente dita parece diferir do trabalho coletivo, etapa de industrialização capitalista, assumindo o aspecto de persistência da identificação tecida também historicamente entre arte e artesanato. Como então utilizar a palavra trabalho para designar tanto a insubordinação artística do século $\mathrm{XX}$ e a subordinação nas fábricas? Como aplicá-la com referência a uma prática transformadora, ao exercício da negação e ao mesmo tempo à produção material e mecânica? Hannah Arendt prefere estudar a "vida ativa" em oposição à "vida contemplativa", propondo que seja desmembrada em "labor", "trabalho" e "ação". Esclarece que o "labor" designa a atividade biologica do corpo humano e E promovido a trabalho na sociedade moderna devido a sua compreensão da "produtividade". O "trabalho" das mãos corresponde à cultura do homo faber e produziu um mundo artificial. "Ação" e a atividade que se exerce entre os homens, sem a mediação de coisas ou da matéria ${ }^{(2)}$.

Aqueles autores que não se satisfazem com a visão economicista do trabalho podem sempre trazer melhores proveitos às reflexões sobre a arte. Dino Formaggio refere-se a "um único e imenso processo de objetivação do trabalho assumido em sua face positiva, processo que só por um certo desenvolvimento histórico da práxis se divide em trabalho
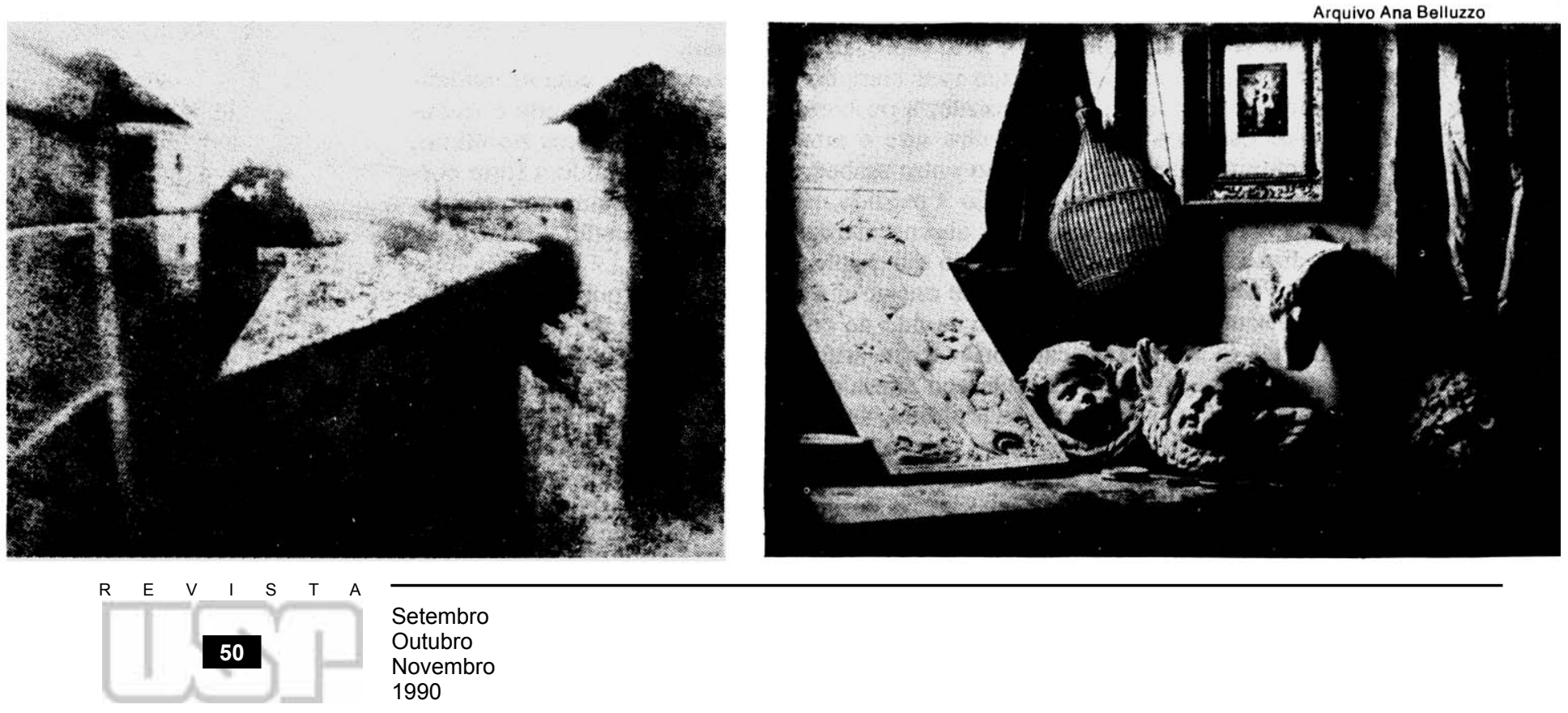
alienante de uma parte e no trabalho artístico e livre de outra". O autor remete à contribuição de Karel Kosik e explora a esfera da "técnica artística" e de suas práticas pré-categoriais para superar a prática meramente repetitiva ${ }^{(3)}$.

Fugindo das concepções abstratas e genéricas de arte, é oportuno lembrar que os artistas aparecem na história ao se emanciparem dos artesãos pelo domínio da ciência. Destacam-se dos artistas mecânicos, tornando-se artistas liberais na época do $\mathrm{Re}-$ nascimento. Lewis Munford chama a atenção para o fato de que no período em que predomina a atividade artesanal não existe diferença entre arte e técnica, pois caminham juntas e se influenciam reciprocamente. "Uma mesma pessoa desempenha ambas as funções, submetendo-se o artista às técnicas de fabricação e operação." No seu raciocínio, o artesão representa a integração do humano no trabalho, tanto no que se refere ao controle e direção das operações técnicas, quanto no que se refere à utilização do tempo necessário para o trabalho, o que lhe possibilita fazê-lo com lentidão ou prazer, de acordo com seu interesse. Disso decorreria a satisfação intrínseca à atividade mesma, quer pelos processos orgânicos envolvidos, quer pela possibilidade de se passar da esfera expressiva para a esfera operativa de concretização do objeto. Mesmo assim, o autor não menospreza a quantidade de trabalho repetitivo - não-espontâneo - exigido do artesão(4).

Em que termos então deve ser considerada a relação entre arte e artesanato? A obra artística, ao se destacar da artesanal e se individualizar, passa a se apresentar como modelo, não como norma, mas como parâmetro para a produção. A obra de arte mostra-se como a experiência mais completa, impondo-se como ápice e verrtice da sociedade baseada no artesanato. $\mathrm{O}$ artefato seguirá os preceitos artísticos durante um longo período, no qual permanecerão interligadas arquitetura, pintura e escultura, ditas belas-artes ou artes do desenho.

O artefato, etimologicamente "o feito com arte", subentende a objetivação humana. A realização manual fixa os gestos do artesão. Ao transformar a matéria, o corpo traça o desenho no seu ritmo e nos seus limites. Ao longo do tempo, a mão, o corpo, vão se amoldando ao trabalho e aprimorando-o. Os conteúdos antropomórficos vêm atestados até hoje nas pernas das cadeiras, nos braços das poltronas, nas bocas dos jarros. A verticalidade das colunas antigas, a representação de cariátides e atlantes figuraram o mesmo sentido desejado abstratamente na proporção e na modulação dos objetos, moldados até hoje à medida humana. Também o ornamento não deixou de ser a sobreposição do homem ao objeto e de afirmar a supremacia do pensamento sobre a matéria, da sensibilidade sobre as intenções práticas. O valor simbólico combinado ao sentido utilitário tornou o mundo mais compreensível, menos estranho, porque moldado à semelhança do homem. A presença de um friso ou de uma barra revelou por sua vez o intuito de conferir integridade ao objeto, harmonizá-lo como um todo em si mesmo.

Supondo as possibilidades do corpo, o trabalho artesanal e artístico utiliza meios de produção imediatos: as ferramentas de que se valem diretamente; os movimentos internalizados da percepção, da memória, da imaginação e do afeto; a orientação dos gestos, atos conscientes ou movimentos pré-conscientes que concernem à prática objetivadora $\mathrm{e}$ à obra humanizada.

\section{Divisão do TrabaLHo}

Nas hipóteses de Klingender, um dos primeiros exemplos da divisão do trabalho é a gravura talhada em madeira, "cujo desenho era em geral preparado pelo artista sobre o bloco de madeira e depois gravado por um artesão". Esclarece o autor que "a técnica inicialmente usada para estampar tecidos foi posteriormente aplicada ao papel, no sé-

Objetos da Exposição Internacional de Londres, 1851
1 Artesanato, arte, indústria, Ana Maria de M. Belluzzo. Tese de doutorado, FAU-USP (inédito).

2 A condiçăo humana. Hannah Arendt. Rio de Janeiro, Forense Universitá. ria, 1987.

3 L'arte, Dino Formaggio. Milano, Mondadori, 1981. pp. 140-60; e Dialéticas do concreto, Karel Kosik. $2^{a}$ ed. Rio de Janeiro, Paz e Terra, 1976.

4 Arte y técnica, Lewis Munford. Buenos Aires, Nueva Visón, 1968, pp. $52,53,56$ e 64 .

5 Arte e rivoluzioneindustriale, Francis D. Klingender. Introd. Enrico Castelnuovo. $2^{\mathrm{a}}$ ed., Torino, Giulio Einaudi, 1972 , p. 90. 
culo XV e seguintes", e teria sido o primeiro modo de reproduzir quadros e desenhos ${ }^{(5)}$.

Os artistas idealizadores e reprodutores vêm de longa data, e o desenho em sua dupla face - design e drawing, ideação e prática executiva - protagonizou este desdobramento. É provável mesmo que a divisão social e técnica tenha ocorrido, de fato, antes mesmo de ser conscientizada e formulada em idéia. Nas palavras de Ferdinando Bologna, na Idade Média haveria uma identificação entre o artesão e o artista; no primeiro Renascimento, uma interação entre eles, e no Maneirismo teria ocorrido o iń́cio da cisão entre artista e artesão. No momento em que eles começam a se distanciar, existiria ainda a consciência da igualdade entre as artes, quando a divisão técnica antecede a divisão social do trabalho(6).

Uma subseqüente separação entre arte e técnica produtiva data da época da industrialização. É preciso sublinhar o mérito de Francis Klingender, cujo livro Arte e Revolução Industrial, escrito em 1947, resgata a discussão do período da indústria manufatureira, de modo a facilitar a compreensão do processo geral de industrialização, freqüentemente discutido com referência a sua fase mecânica. Sob essa ótica, a industrialização compreende as técnicas artesanais em que baseia a sua primeira fase, durante a qual absorve a experiência do artesanato, procedendo ao mesmo tempo a sua desorganização. Considerar a etapa que precede a mecanização é admitir a convivência entre artesanato e indústria. Klingender tem a sua atenção voltada para as primeiras décadas vitorianas, momento das "grandes esperanças" suscitadas pela Revolução Industrial (em torno de 1750-90), anterior à "idade do desespero".

As exigências quantitativas dessa etapa da industrialização contam com a organização racional do trabalho - divisão, parcelamento e especialização -, devendo-se considerar a reprodução e a repetição manual. É precisamente a base técnica artesanal em vigor na época da decomposição do processo de trabalho artesanal que estabelece os limites do período manufatureiro, demonstrando que o rompimento com uma determinada forma de organização do trabalho não corresponde ao abandono das técnicas operativas que lhe são características. No referido período, arte e indústria serão grandes aliadas, ainda que se acabe por bombardear o sentido do que é artístico e ainda que a unidade do produto artesanal venha a ser destruída pelo trabalho parcelado. Somente quando ultrapassada a etapa manufatureira
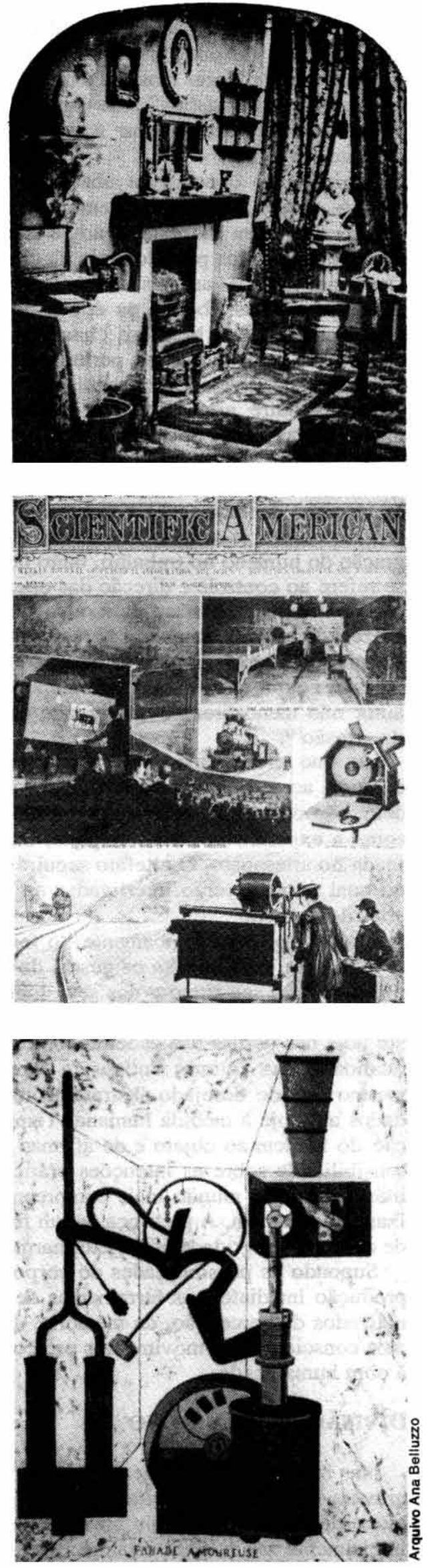
é que a oposição entre arte e indústria irá se apresentar como divergência entre os procedimentos manual e mecânico.

$\mathrm{Na}$ primeira industrialização, ao menos pelo que transparece do clássico modelo inglês, conciliam-se as exigências científicas e tecnológicas e as formulações artísticas. Ilustra a questão a célebre manufatura inglesa de louças aperfeiçoada por Josiaph Wedgwood, chamada significativamente Etrúria, de 1766, que conta com artistas como Flaxman e Weber. A maior parte do trabalho é realizada à mão, e utiliza-se energia a vapor para misturar os materiais e acionar o forno, como descreve Bologna. Os motivos gregos, etruscos e romanos adotados resultaram de pesquisas científicas sobre as artes decorativas do passado e, o que é também importante, ajustaram-se a aplicação das têcnicas industriais. A concepção geral do neoclassicismo sobre as artes figurativas constituiu uma via para essa cooperação; basta lembrar que os neoclássicos valorizam a ideação, o desenho, e defendem o rigor da execução técnica, tendendo, como se pode notar, para o que na sociedade moderna se conhece por design. A cerâmica de Wedgwood evidencia o consciente e desejado acordo entre beleza e utilidade, para o qual já alertaram vários estudiosos. Bologna reconhece que foi exatamente a compreensão dos valores funcionais do ornamento que conferiu às louças de Wedgwood a idoneidade racional com que são hoje internacionalmente reconhecidas. No "momento funcional dos modelos antigos das manufaturas inglesas", afirma o autor, traduz-se uma síntese entre ornamento e funcionalidade da primeira industrialização ${ }^{(7)}$. O mesmo poderia se falar da racionalidade neogótica, assinalando que, por meio dessa revivescência da Idade Média, também se examinou o caráter construtivo da arquitetura gótica.

A industrialização do utilitário a ele agregou um "valor decorativo" eminentemente artístico. Isso mostra que a arte era vista, também, como um ingrediente necessário para dar valor mercantil aos produtos manufaturados ${ }^{(8)}$. $\mathrm{O}$ período compreendido entre $\mathrm{o}$ artesanato e a indústria propagou a fórmula dos objetos amplamente desejáveis por que úteis e belos. Por outro lado, a exacerbação, o destaque dado ao valor decorativo do objeto utilitário, nessa época, revela um dos aspectos mais desconcertantes da interação entre arte e indústria. Evidencia-se a existência de uma indústria artística ajustada ao feitio de um determinado público com exigências práticas e utilitaristas, para o qual a falsa consciência do valor artístico apresentava a arte como propriedade objetiva e material do objeto decorado, signo de valor e riqueza. Em suma, ao lado da síntese realizada pelas manufaturas artísticas, existiu a afetada indústria do ornamento. E se certas contribuições puderam facultar a aproximação da tradição artística ao produto industrial, inegavelmente foi a tecnologia científica que garantiu as inovações.

A compreensão da indústria manufatureira ilumina ainda certos setores de atividades existentes ainda hoje, como é o caso de certa arquitetura e de setores da indústria da construção. Da mesma maneira esclarece a sobrevivência do artesanato enquanto técnica, quando a sociedade já se apresenta predominantemente industrializada.

\section{INDÚSTRIA, TECNOLOGIA E ARTE}

"A ciência física, principalmente a mecânica, substitui a arte como força propulsora e diretiva do processo teórico", a partir do século XVII. Como afirma Argan, a "ciência assume o comando (...) tolhendo a arte no campo da atividade inventiva"(9). A reorganização da produção a partir de métodos da ciência e da tecnologia dispensa conteúdos artísticos, como demonstram as inovações na metalurgia, a descoberta de materiais e procedimentos, as novas máquinas, as obras dos engenheiros, as pontes e estradas.

Há conquistas também no campo da representação visual, marcando o surgimento da tecnologia da imagem. Basta lembrar a litografia e a descoberta da fotografia provocada pela lito. A heliografia, "escrita do sol", reprodução automática da natureza, foi conseguida por Niépce, que era litógrafo, ao transportar o desenho sobre a pedra. O próprio Niépce chamaria suas reproduções da realidade de "pontos de vista". Talbot concluiu a invenção. Utilizando uma câmara negra para fazer croquis durante suas viagens, encontrou "um procedimento químico pelo qual os objetos naturais podiam se delimitar eles mesmos, sem ajuda de um lápis". Descobria a possibilidade de fixação da imagem luminosa, registrando o caminho de sua invenção no livro $O$ lápis da natureza, de 1844.

As heliografias e os pontos de vista de Niépce, $O$ lópis da natureza de Talbot são evidências das aproximaçōes entre arte e ciência no momento em que se formularam os novos caminhos da representação da natureza. $O$ nascimento dessas técnicas a partir de
6 "Dalle arti minori allindustrial design". Ferdinando Bologna, in Storia di una ideologia. Bari, Laterza, 1982.

7 Op. cit., F. Bologna. pp. 150-3.

8 Art and industry, Aaron Scharf (org.). Edinburg. The Open University, 1971 Edinburg, The Open University, 1971 34), p. 11.

9 Proggetto e destino, Giulio Carlo Argan. $2^{\mathrm{a}}$ ed.. Milano, Mondadori, 1968 , p. 28.

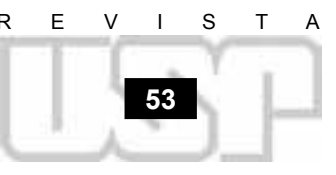


objetivos da representação, sejam eles conveniências do próprio trabalho, sejam alvos naturalistas, respondem a velhos anseios dos artistas. Mas o advento das novas técnicas de registro e reprodução de imagens não é saudado como invento artístico. A litografia, a fotografia e a cinematografia, que se sucedem, são inseparáveis da sua dupla natureza técnico-artística. E como meios de representação e reprodução terão serventia para outras atividades do homem, como exemplifica a fotografia que irá se aplicar à industrialização como um todo.

Diante das conquistas científicas para a produção, as artes aplicadas à indústria revelam o deslocamento do lugar da arte. A expressão applied art surgida na Inglaterra, em torno da metade do século XIX, tem implícita a ligação entre arte e indústria. Enquanto conceito, as artes aplicadas se opõem às artes puras. No lugar dos objetos que eram artísticos pela sua fatura, existem agora os objetos técnicos. Mais do que em qualquer outra época, o artístico é reduzido a agregado ornamental. $O$ princípio artístico, que havia sido uma dimensão estruturante do objeto, perde a posição central, chegando a tornar-se um atributo externo a esse mesmo objeto. As "artes maiores", que haviam sido modelos para a produção artesanal e parâmetros para a experiência, passam a ser meras fontes de motivos figurativos ${ }^{(10)}$.

As transformações da produção incluem as mudanças da atividade artística - tanto de seu lugar quanto de sua relação com as outras atividades humanas -, e atingem sua estrutura e finalidade. A nova situação se manifesta na forma do objeto e nos novos agentes que assumem as decisões sobre o produto: empresários, artistas e designers. Sobre esse assunto, Argan pondera que "a superação da tecnologia do artesanato, que

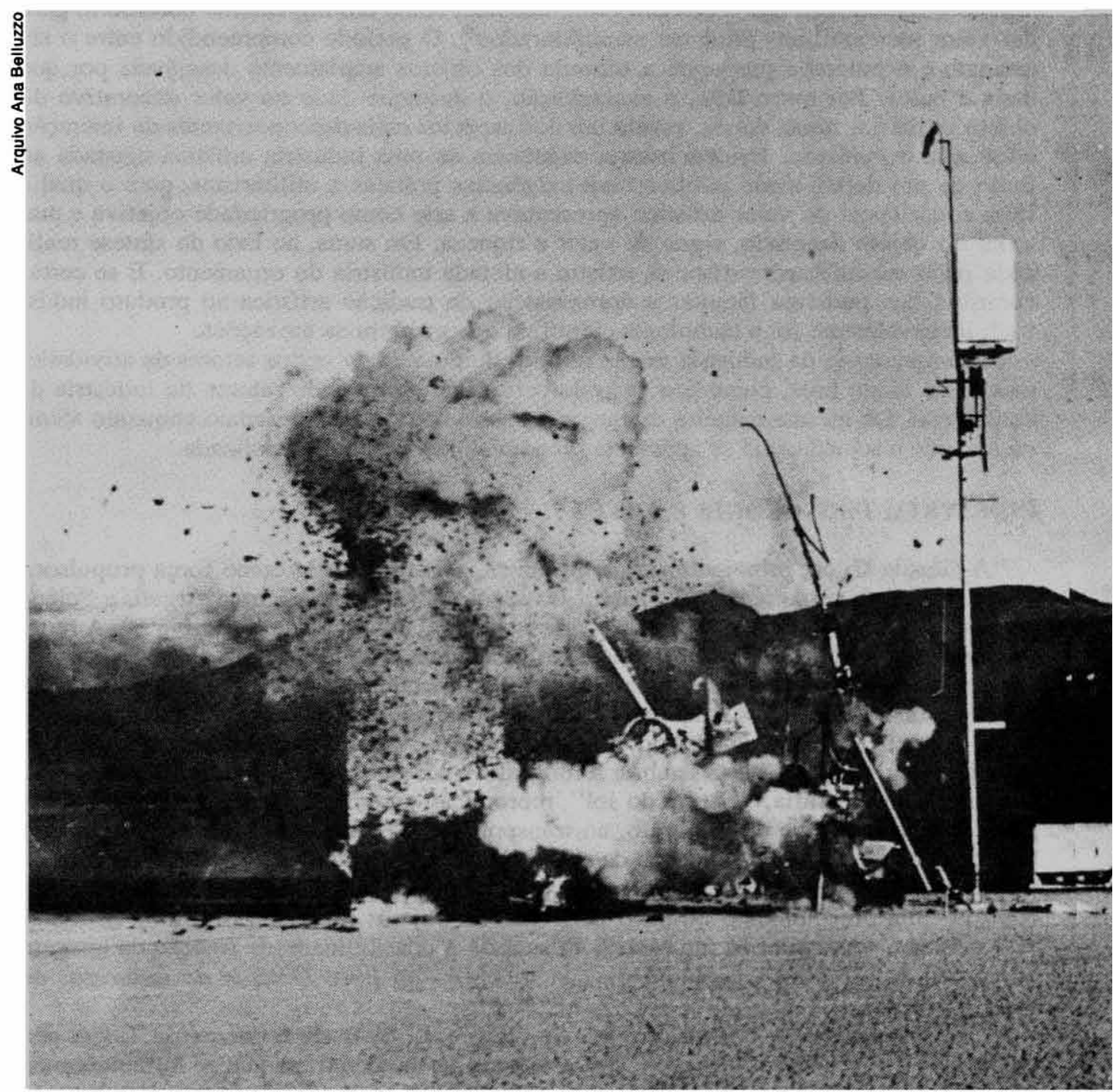

Ao lado, Estudo n? 2 para o fim do mundo, de Jean Tinguely. Máquina autodestrutiva, deserto de Nevada (EUA, 1926); na página ao lado, Escultura radiofónica com pluma, do mesmo autor, 1962

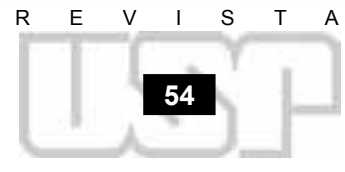


utilizava a matéria e imitava os processos da natureza, pela tecnologia industrial que age sobre a natureza, transformando rapidamente o ambiente", está na raiz da crise da arte moderna. Esse fenômeno se associa à exclusão dos artistas do sistema técnico-econômico de produção e ao fato de virem a se tornar "intelectuais burgueses em relação de tensão e freqüentemente de áspera polêmica com a mesma classe dirigente da qual fazem parte". Seu ponto de vista compreende os aspectos sociais e tecnológicos do desenvolvimento industrial. Encontra no pensamento iluminista o momento de ruptura de uma concepção de mundo atingida pela visão materialista da natureza, que não se "imita" ou se "repete" pela arte, mas se "transforma" através dela. Inclui-se, portanto, no raciocínio de Argan, a idéia de que o fím da mimese se liga ao surgimento de uma relação inédita entre homem e matéria ${ }^{(11)}$.

Nas sociedades de vértice artístico tudo era feito com arte, tanto móveis, utensílios e outros objetos de uso prático, quanto aqueles de significado e uso simbólico, tais como a pintura e a escultura, que se integravam na unidade do espaço arquitetônico. A arte cuja consecução era voltada para fins práticos não estava tão distante da atividade desinteressada e contemplativa, como acontece hoje. Diferentes em seus fins, assemelhavam-se mediante certos aspectos do desenho. O componente estético cotava a obra com um valor de trabalho objetivado, isto é, um valor artístico.

$\hat{E}$ provavel que a identificação entre arte e determinados procedimentos técnicos tradicionais tenha ocorrido paralelamente às novas conquistas técnicas e à descoberta de materiais e processos. Estes não teriam sido apropriados artisticamente, e a possibilidade de virem a sê-lo dependeria, em última análise, de oportunidades para experimentar e sedimentar por seu meio novas dimensões formais. Os materiais não são a priori artísticos, nem os processos. Artística é a apropriação, é a relação entre a idéia e a têcnica de execução.

\section{INVERSÃO DE VALOR}

As profundas mudanças na orientação da produção - ocorridas desde o século XVII e explicitadas em nova ordem a partir do século XVIII inglês -, ainda que tributárias do saber-fazer artesanal, dele se distanciam na acelerada industrial do meio do século $\mathrm{XIX}$, com as possibilidades abertas pela descoberta de materiais e técnicas. Na etapa da mecanização, a arte já não poderá mais fornecer os moldes técnicos para a produção, que passará a contar com a tecnologia científica. Giulio Carlo Argan compreendeu com propriedade que desde então a arte passará a constituir um modelo cultural para a sociedade. Entretanto, a dissolução das corporações de ofício e da ordem social própria do trabalho artesanal bem como a organização da atividade industrial capitalista não impedem o aproveitamento de têcnicas e procedimentos operacionais acumulados pelos séculos de experiência.

Argan entende que "a revolução industrial não consiste tanto na introdução de novas fontes de energia e modos racionais de organizar o trabalho quanto na inversão da hierarquia de valores"(12). Sustenta que o artesanato atinge seu ponto mais alto realizando o máximo de qualidade com o mínimo de quantidade, chegando a seu nível mais baixo no esforço para produzir o máximo de quantidade com o mínimo de qua-

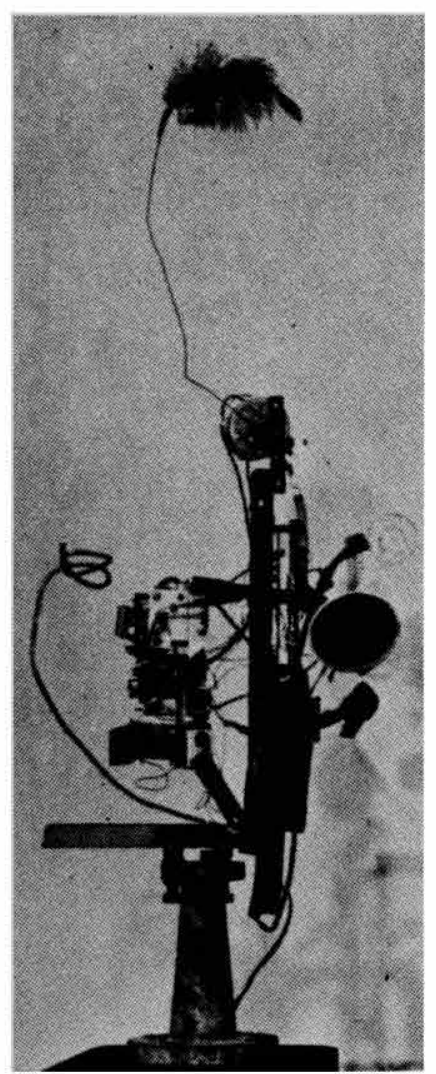

10 Dizionario della critica darte, Luigi Grassi e Mario Pepe. Torino, UTET, 1978, v. 1. pp. 48-9.

11 L'arte moderna 1770-1970, Giulio Carlo Argan. $2^{6}$ ed., Milano, Florenza, Sansoni, 1978, p. 8 op. cit., cap. I, pp. 9-74.

12 Proggetto e destino, idem. pp. 22-4.

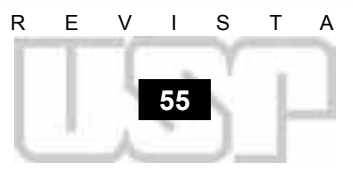


lidade. A peça única, a obra de arte, corresponde, nesse raciocínio, ao mais alto valor para a produção artesanal, enquanto para a indústria o valor mais alto é a série, podendo o objeto ser repetido sem perder a qualidade.

Na formação da obra constitui-se o valor artístico e artesanal, enquanto no produto industrial o valor se realizará na ampliação de seu consumo. A obra pautada em consideração à sua dimensão econômica e a obra pautada pela finalidade artística traduzem também a enorme diferença de abordagem.

A desconsideração das tradições artísticas e a perda da qualidade dos produtos desencadearam respostas. A reação romântica antimecanização promove um recuo à Idade Média. $\mathrm{O}$ movimento pré-rafaelista internacional tem lugar na primeira metade do século XIX na Alemanha, na França e na Inglaterra, restabelecendo corporações e escolas, mobilizando as artes e ofícios. A prática da Escola Lionesa de decoradores religiosos, os nazarenos alemães, o restabelecimento das guildas em Westmoreland, com adoção de modelos para fiação copiados dos campanários de Giotto, estarão na base das teorias neogóticas tanto de Ruskim, que integrou o pensamento pré-rafaelista, quanto de Pugin. Ruskim defende o ornamento como a dimensão espiritual contrária ao caráter maldito do trabalho, para garantir o prazer do espírito - como se pode deduzir da leitura das Pedras de Veneza - e é contra injunções políticas e econômicas nas artes ${ }^{(13)}$. O medievalismo de William Morris é diverso. Devido às suas convicçōes socialistas, acredita na possibilidade de mudar as relaçōes de trabalho. Defende a auto-realização pelo trabalho, o resgate da alegria e do prazer no fazer. A experiência prática de Morris está na origem do desenho industrial moderno. Os dois críticos dos objetos da era industrial vitoriana têm o mérito de trazer à tona questões relativas à arte enquanto trabalho.

Data da mesma época o surgimento do artista romântico que fornecerá a imagem, por excelência, do artista moderno, saída do momento de crise, sobrevivente ainda hoje. Nascem a autoconsciência do artista e a consciência da arte em conflito com o mundo: o artista excêntrico, deslocado do aparato produtivo. A figura noturna, desencontrada da jornada de trabalho, que sonha acordada enquanto os outros dormem fatigados, é uma imagem meio caricata, criticada mas simultaneamente desejada pelo homem comum, posteriormente uniformizado na sociedade de massa. $O$ artista será seu alter ego. Cresce o arbítrio do artista, autorizado a sonhar e imaginar mais, à medida que vê transformar-se lentamente a situação da obra definida no regime de encomenda. Provavelmente, a relação com um novo público e as incertezas do trabalho para o mercado dão a outra face da "independência" conquistada.
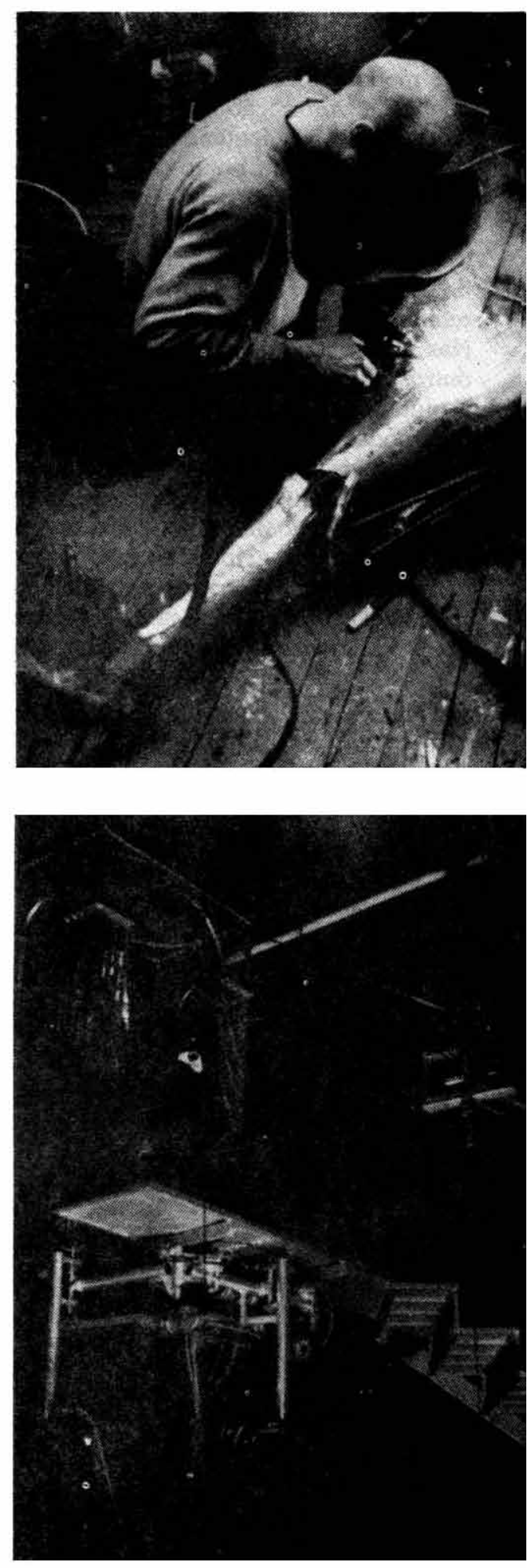

Acima, Jim Whiting solda uma escultura para o parque Luna Luna (Hamburgo, 1987); ao lado, um trabalho de Whiting para o mesmo parque

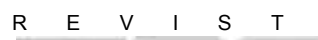

Setembro

Outubro 

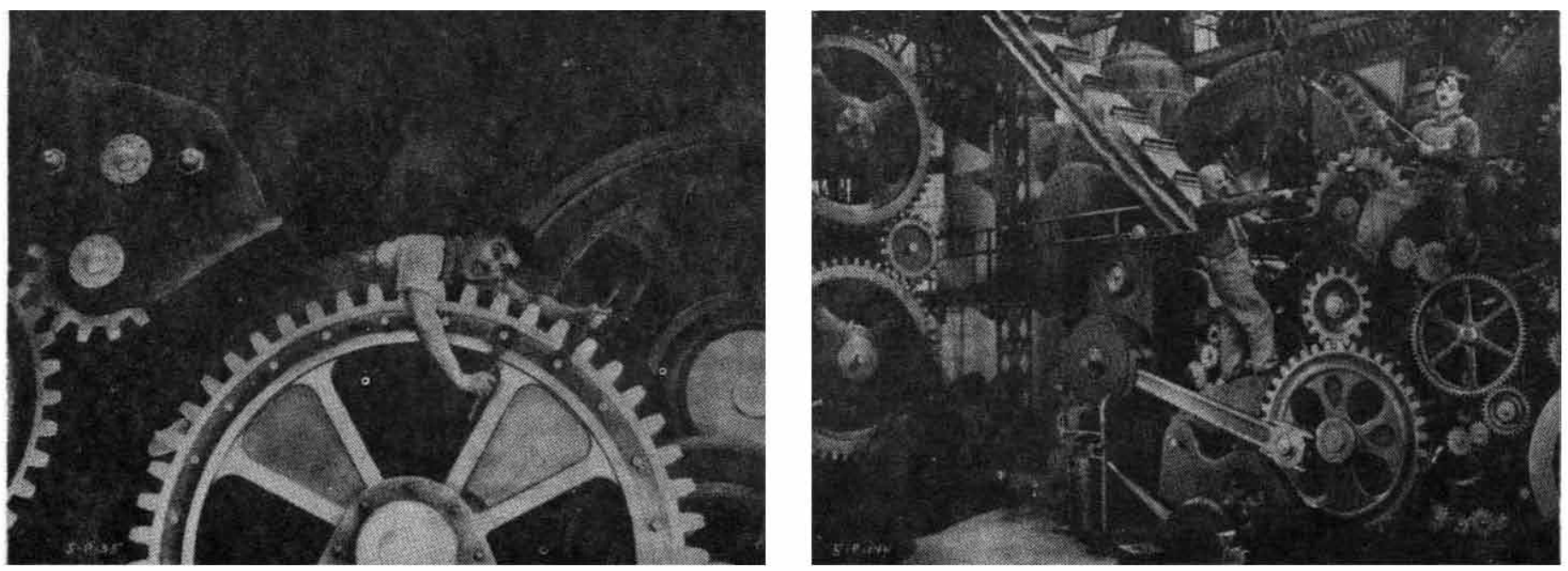

Seqüência do antológico Tempos modernos, filme de Charles Chaplin de 1936
16 Op. cit., Dino Formaggio. pp. 120-7. De Palma indica dois significados de "allenacho", baseado om Marx" "a 'alienaçăo do produto' resultante do consumo de uma mercadoria que capitalista adquiriu e a 'alienaçâo do trabalho', no sentido de que, na $\infty 00$ peração, o operário perde o controle sobre o seu proprio trabalho" "La organizacion capitalista del trabajo on ganizacion capitalista del trabajo en l capital do Marx. Armando do Pal ma, in La division capitalista del tra bajo. $2^{2}$ ed., Buenos Aires, Pasado Y Presente, 1974, p. 8). nômica e também espiritual) da propriedade privada, o estado de alienação e de dependência é lei, portanto também as necessidades, como aquelas primárias, da fome brutal, e secundárias, como o afeto ou o conhecimento, tornam-se cada vez mais uma alienação, uma força alienadora do homem"(16).

Nas condições do mundo pós-industrializado, a simbiose entre os homens e seus instrumentos de trabalho sobrevive ainda hoje na modalidade do saber-fazer artístico. A memória da experiência direta da construção do objeto foi guardada pelos artistas e muitos deles seguem utilizando os meios imediatos do corpo, valendo-se da intuição e usando os sentidos como avalistas finais do resultado do trabalho. Manipulam afetivamente a matéria e domesticam processos. Enfim, buscam incessantemente relacionar o pensar ao fazer.

\section{ESPECIALIZAÇÃo E AUTONOMIA}

O projeto de autonomia das artes manifestara-se inicialmente com a recusa dos valores extra-artísticos da obra, ou seja, com o abandono dos conteúdos religiosos, morais e sociais, e pela afirmação da arte pela arte. Logo se apresentou como uma recusa de valores de outras artes.

O recorte dos campos de atuação da nova plêiade de artistas e as distâncias entre eles têm correlatos teóricos nas doutrinas estéticas que dão substância ou esteio para tais deslocamentos, baseados na autonomia dos valores artísticos e na autonomia das linguagens. Nas artes figurativas, a rigor, a autonomia remonta à criação da estética, disciplina dos meados do século XVIII que tinha a beleza por fim proprio da arte, distinguindo-a, portanto, dos aspectos contingentes e necessários ou utilitários. Nos tempos da primeira industrialização, o gráfico, o artífice e o fotógrafo figuram ao lado do artista plástico, que passa a atender solicitações do incipiente mercado. Reunidos sob um sistema unitário das artes, todos vão se especializando, o que acabará esgarçando os pontos de contato e união entre suas atividades: a imagem plástica, a imagem gráfica, a fotografia, a imagem do objeto tenderão a formar campos próprios. Esse desenvolvimento por cursos diversos e mesmo divergentes do que antes estava solidário é o argumento mais contundente da explosão de uma cultura e da formação de outra.

O fotógrafo e depois o cinegrafista tomam para si incumbências destinadas anteriormente ao pintor, quando este era o maior responsável pela produção de imagens. Os novos profissionais dominam de início as possibilidades dos novos processos de trabalho, vindo posteriormente a se especializarem em tarefas determinadas da feitura da foto e do filme. A intenção estética do resultado não poderá dispensar a unidade de comando, e a direção artística é desafiada a sintetizar e rearticular trabalhos técnicos e artísticos parcelares. Nāo se trace nenhum paralelo com o regime das corporaçōes, pois a empresa moderna não seguirá hierarquia de competência, como a que tinha no mestre o condutor da oficina: o comerciante conduz o novo empreendimento. Por sua vez, as vanguardas modernas que sucederam ao romantismo, responsáveis por intensa transformação dos hábitos visuais e das heranças artísticas, consolidaram um novo lugar para o artístico. A transformação das técnicas da arte realizada pelos artistas impressionistas especializa a pintura no campo da visão, desprezando valores tectônicos e corpóreos das artes figurativas. As contribuiçōes de teor expressionista distanciam as artes das formas gerais de trabalho, exacerbando gestos e pulsōes do corpo, colocando-se na de- 

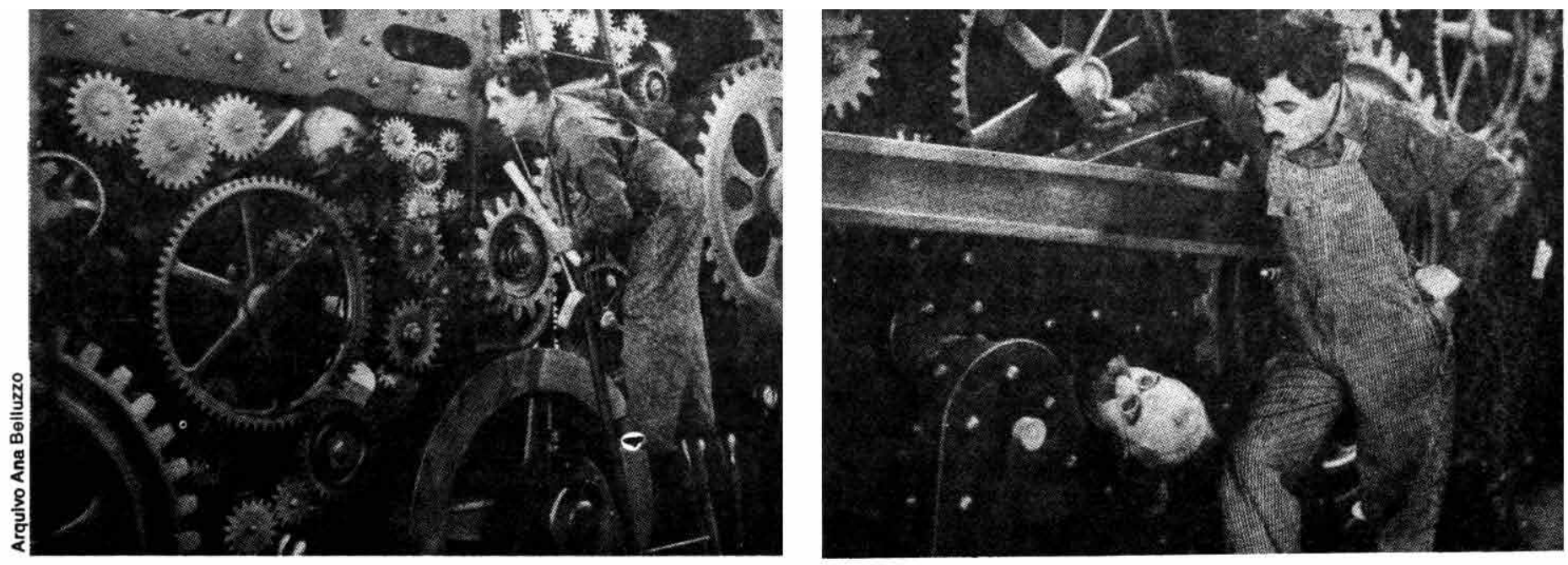

fesa do indivíduo, situando-se entre as poéticas que se valem da introspecção e apresentam uma visão dramática da condição do homem. Liberam-se enunciados primordiais, pré-categoriais, anteriores às articulaçōes da linguagem também pelos processos surrealistas. $\mathbf{O}$ artista passa a jogar com os proprios mecanismos interiores, com o acaso e o sem-sentido e expōe o homem desconhecido dele mesmo.

No caminho da abstração, os princípios gerais cubistas buscam ultrapassar o mundo das aparências. Alguns desses artistas ainda demonstram um certo otimismo. Fernad Léger canta o espetáculo da cidade moderna. No combate das tradiçōes artísticas, os futuristas encaram um novo espaço e tempo: a máquina e a velocidade. Artistas construtivos, com base no cubismo e no futurismo, desprezam valores do conhecimento mimético e da manualidade, afirmando uma racionalidade abstrata. Descobrem e valorizam a estrutura técnica do objeto, reconceituando-o e almejando novas possibilidades de cooperação entre arte e produção geral ou mesmo entre as artes.

A riqueza de respostas oferecidas à situação crítica da arte, nos trinta primeiros anos do século, contém a radicalidade das démarches parciais e sectárias. Os automatismos gestuais são levados à ação incontrolável que fala por Jackson Pollock, expoente da action painting. A autovingança das máquinas mostra-se por meio de Tinguely. Dessa radicalidade decorre inclusive a sua dimensão poética. Das ironias de Duchamp ao artista conceitual dos anos 70 , desmaterializador da arte, confinado na missão de idealizador, são feitas alusōes aos impasses da própria arte. Ao lado do artista liberado da produção, que tem um juízo de valor negativo com relação à sociedade, e que passa, portanto, a oferecer um parâmetro cultural para a existência, afirma-se o artista mediador, que, empenhado em reunir a arte e a sociedade, por meio do projeto, rompe o mito da arte pura, abandona o papel de intelectual e se transforma em técnico profissional do projeto, aceitando a tecnologia industrial da produção. $O$ valor artístico, que no passado existiu na execução material do objeto, tornado valor ornamental acrescido ao objeto na Época das artes aplicadas, irá se integrar à totalidade funcional do objeto e será de teor abstrato, na concepção do começo do século XX.

Caminha-se incessantemente rumo às especificidades: desde as críticas de Adolf Loos contra o ornamento e a cultura dos arquitetos, junto com a defesa estética de valores modernos como a solidez e o princípio da utilidade, até o design constituído em um campo próprio de experimentação, pela prática ensejada por Walter Gropius na Bauhaus. Da mesma maneira, o específico filmico é desenhado por Eisenstein na teoria da montagem. As particularidades dos campos de atividade "artística" são, em resumo, o reconhecimento de técnicas operativas próprias, que assumem uma dimensão central e um papel especializador.

\section{REPRESENTAÇÃO E REPRODUÇÃO}

Devemos ajustar os termos da complexa relação entre arte e trabalho, de acordo com uma compreensão abrangente dos séculos XIX e XX.

A nova amplitude da questão estética anula os parâmetros dados pelo saber-fazer artístico que deu suporte técnico à primeira industrialização. De uma maneira geral, podese entender que toda produção de bens é inseparável de seus aspectos estéticos, sejam eles resultantes de uma intenção projetual, sejam essas qualidades reconhecidas $a$ pasteriori, na apreensão sensível do objeto. Como a história ensinou, os aspectos centrais da

riori, na apreensăo sensivel do objeto. Como a historia ensinou, os aspectos centrais da 
arquitetura moderna do século $\mathrm{XX}$ não nasceram das tradições das belas-artes, mas da atribuição de valor estético à obra dos engenheiros.

$\mathrm{O}$ desenvolvimento industrial, tendente à multiplicação e à diversificação dos produtos, recriou totalmente o ambiente no qual o homem vive. A imagem do objeto veio a se tornar o lugar privilegiado para o argumento da sedução e estímulo ao consumo, de acordo com as exigências capitalistas da obsolescência planejada.

O grande alargamento dos lugares da arte no mundo contemporâneo, a crescente ampliação de procedimentos artisticamente valorizados, a inserção e a coexistência da atividade artística, junto às outras esferas de atividade, têm por equivalente a pulverização do artista e a cotidianização da arte. Ao deixar de constituir modelo para a experiência, a arte se banaliza, se dilui e se destrói, enquanto a exigência da arte convida artistas a fazerem renascer as tradições.

$\mathrm{Na}$ conhecida expressão de Edgar Morin, o século XX realiza uma segunda industrialização: a industrialização do espírito, fazendo uso das novas possibilidades técnicas para a produção do domínio interior do homem, até mesmo de seus sonhos ${ }^{(17)}$. A atividade de elaboração cultural tornada uma das áreas da produção é identificada criticamente, em meados do século, pela expressão indústria cultural. A expressão é cunhada por Adorno e Horkheimer para indicar um fenômeno já moderno: a nova forma de organização e planejamento da atividade cultural, no tocante à organização social do trabalho, e não à nova escala distributiva do produto da cultura, que fornece então farto argumento para os mais entusiastas defensores dessa indústria, cujos resultados pseudoartísticos são discutidos pelos autores de Frankfurt. Advertem para o fato de que "o conceito de técnica que reina na indústria cultural não tem em comum mais do que o nome com aquilo que vale nas obras de arte. Este se refere à organização imanente, à lógica interna. A técnica de distribuição e reprodução mecânica permanece, ao contrário, sempre exterior a seu objeto" e "é parasita da técnica extra-artística de produção de bens materiais". A noção de indústria cultural está definitivamente referida ao capitalismo industrial maduro que abrange o setor da produção cultural ${ }^{(18)}$. Tanto Adorno quanto Morin situam seu aparecimento a partir da cinematografia e entendem ser o filme o setor central da indústria cultural, caracterizada pela metodologia técnica, pela assimilação das formas industriais de organização do trabalho com sua imperiosa divisão. Gradativamente, a empresa jornalística e editorial, a indústria cinematográfica, a empresa radiofônica e a rede televisiva irão apresentando os contornos da empresa moderna e expandindo gigantescamente o consumo cultural.

Cabe finalmente considerar que, no curso das inovaçōes técnicas, as artes foram afetadas por novos processos de produção simbólica, que envolvem tanto o plano da representação como aquele da reprodução da imagem. O primeiro momento diz respeito à linguagem; o segundo, à reprodução da obra artística.

Para ilustrar esse pensamento, um recuo às origens da linguagem e da consciência mostraria o primeiro gesto humano, indicativo, que aponta a coisa. Depois, o nascimento dos substitutos do real: o som, a palavra no lugar do objeto; a grafia do desenho, a materialidade da palavra, a escrita. Todos são signos que constituem o universo da linguagem: do pensado e do referido pelo homem. Os substitutos do real mostram o homem transformando e multiplicando o mundo pelos signos, o homem produzindo e reproduzindo imagens. $\mathrm{O}$ registro fotográfico, o desenho na pedra litográfica, como também a modelagem, inauguram o trabalho industrial de reproduçāo e repetição de objetos, atingindo em cheio a linguagem e a concepção da obra enquanto obra única e modelar. Esse universo da reprodução, com know-how técnico-artístico compreende os recursos da reprodução tipográfica da palavra escrita, da reprodução fotográfica da linguagem visível, da reprodução sonora da linguagem audível, da reprodução cinematográfica do espaço e do tempo e, finalmente, da reprodução holográfica.

O saber-fazer artístico é apropriado pela indústria cultural e opõe-se a ela. Cindido em saber, por um lado, e fazer, por outro, recua ao momento primeiro, mágico, da linguagem. Regride às operações psicológicas. Despreza a visão linear do tempo e a ilusão do progresso que comemora o enterro da arte. Reaviva tradições por movimentos de compensação das carências humanas. Mostra-se inseparável da necessidade de objetivação humana. Por isso mesmo o know-how artístico segue mimetizando os próprios procedimentos técnicos e criativos. 